\title{
EL PASEO AHUMADA DE ENRIQUE LIHN, ADAPTADO AL CÓMIC POR LIVÁN: AFFORDANCES Y TENSIONES EN EL PROCESO DE ADAPTACIÓN
}

\author{
EL PASEO AHUMADA, FROM ENRIQUE LIHN, ADAPTED BY \\ LIVÁN: AFFORDANCES AND TENSIONS \\ IN THE ADAPTATION PROCESS
}

\author{
Julio I. GUTIÉRREZ GARCÍA-HUIDOBRO \\ Universidad Adolfo Ibáñez \\ julio.gutierrez@uai.cl
}

Resumen: Este trabajo revisará cómo Liván realiza la transposición de El Paseo Ahumada. Desde las reflexiones de McHale (2010), se revisará cómo la segmentación de la poesía puede ser replicada en el cómic, y cómo los media affordances influyen en la transposición. Se buscará analizar la mirada del adaptador y cómo esta tensiona con los affordances y los modos de construcción discursiva secuencial. Este trabajo es relevante pues ofrece nuevas reflexiones en torno al proceso de transposición de medios tan dispares como el texto lírico y el secuencial, un tema escasamente se ha estudiado en la teoría de la adaptación.

Palabras clave: Adaptación. Media affordances. Segmentividad. Poesía. Cómic.

Abstract: This paper intends to study how Liván achieve the transposition 
of El Paseo Ahumada. Through McHale's (2010) conclusions, we will review how poetry segmentation can be replicated into comics, and how the media affordances influence in the adaptation. It is also intended to analyze the source view from the adapter, and how it tensions with the affordances and the modes of discursive construction in comics. This work is relevant because it offers new thoughts around the process of adaptation in such media as poetry and comics, a subject that it's been sparingly studied in adaptation theory.

Key Words: Adaptation. Media affordances. Segmentivity. Poetry. Comics.

Al estudiar adaptaciones, quien realiza el análisis suele enfrentar el problema desde la diferencia: hay dos medios distintos que generan productos independientes entre sí pero que guardan un vínculo en común: el contenido, el relato que se reproduce, que se enuncia siguiendo las reglas del medio en que se realiza dicha enunciación. Las reflexiones de Chatman (1980) y McFarlane (1982) a este respecto ofrecen grandes aportes al modo de concebir la adaptación como una práctica que genera un producto nuevo que, por un lado, toma distancia de su fuente para atender a las propiedades estructurales del medio en que se desarrolla el hipertexto, y por otra parte, mantiene un vínculo con su fuente que permite relacionar ambas obras. Ese es el planteamiento de Linda Hutcheon (2006), quien propone que la adaptación debe ser entendida como "repetition without replication" (9), siguiendo esta línea de razonamiento. En este sentido, la diferencia, más que un eje posible de acción o análisis es un elemento tensor al indagar en las relaciones entre dos representaciones, o más bien enunciaciones, de un mismo relato. La diferencia enriquece de algún modo la reconstrucción discursiva de la transposición, de modo que una versión fílmica de una novela será una contribución en la formación de las representaciones que los receptores se hacen de dicha narrativa. Julie Sanders (2006) se 
refiere a este fenómeno aludiendo al concepto de narrativa incremental, es decir, un modo de expandir el contenido de una obra a través de los rasgos distintivos de la retórica del medio del hipertexto.

Ahora bien, la literatura dedicada a la teoría de la adaptación ha centrado su atención en los vínculos y tensiones entre diversas formas narrativas, como la literatura, el cómic y el cine. No obstante, existen diversas obras que buscan reescribir textos de formatos que no necesariamente siguen una estructura diegética. Al observarlas, surge la problemática que suscita la incomodidad de hallar el modo correcto de abordar el análisis, teniendo en cuenta de que el vínculo esencial de lo causal se pierde.

\section{DE LA POESÍA AL CÓMIC: ALGUNAS NOTAS SOBRE LA SEGMENTACIÓN Y LOS AFFORDANCES}

El medio secuencial, en toda su plasticidad, puede desarrollar discursos no necesariamente narrativos, aunque lo más común sea precisamente un desarrollo secuencial. Desde Barbieri (1993) hasta Groensteen (2007) y otros autores y creadores, como Dino Buzzatti (1970) exploraron las propiedades visuales y compositivas de la plancha con miras a explorar las posibilidades de alejar al cómic del "área de confort" de una buena parte de la crítica. En este sentido, los aportes de Baetens (2011) a partir de su revisión de la abstracción en el cómic y los modos en que inconicidad y plasticidad entran en tensión y alejan el foco de lo narrativo son una fuerte base para explorar las proyecciones poéticas del medio desde la artrología (Groensteen, 2007). De acuerdo con Tamryn Bennett, el cómic permite estas flexibilidades, cuya evidencia es obras que experimentan con la topología visuo-verbal que comparten poesía y cómics, que dan como resultado un producto no necesariamente secuencial (Bennett, 2014: 109).

Por lo anterior, pensar en transposición de poesía a cómic confirma 
estas reflexiones desde el campo de la adaptación, en que se ponen en tensión dos soportes distintos (texto escrito y el híbrido visual-textual del cómic) y formas de enunciación diferentes. El trabajo de Liván sobre El paseo Ahumada ${ }^{1}$ de Enrique Lihn desmiente la evidente falacia de la incompatibilidad de soportes en el proceso de transposición, que podría relacionarse con la que Thomas Leitch (2003) identifica a la luz de las relaciones entre literatura y cine: creer que una obra debe necesariamente replicarse idénticamente en otro lenguaje es absolutamente ingenuo. Al trasladar una obra de un medio a otro, sea ésta cual sea, es inevitable que en el proceso el discurso sufra una serie de alteraciones, la gran mayoría de ellas en función del formato del medio, pero también de las necesidades del receptor: sirviéndose de la metáfora del conducto de Jakobson, MarieLaure Ryan plantea que los medios no son meros "tubos" por los que pasa el contenido de la obra, sino que más bien son filtros a través de los cuales el contenido de la obra se verá modificado.

En la introducción de Narrative across media (2011), Ryan explica su postura en relación al estudio de la transmisión de narrativa a través de distintas plataformas discursivas, por ejemplo en el caso de las transposiciones. Para la investigadora, la postura de Ong respecto a la obsolescencia de la metáfora del conducto (2006: 170) para entender esta relación es crucial. Ella da un paso más allá y plantea una reflexión que puede iluminar lo que aquí pretende plantearse sobre la adaptación en dos lenguajes tan distintos como lo son el cómic y la poesía:

different media filter different aspects of narrative meaning. Far from being completely undone at the end of the journey, as Ong suggests in his critique, the shape imposed on the message by

\footnotetext{
${ }^{1}$ Es pertinente hacer la distinción entre el título de la obra de Enrique Lihn transpuesta por Liván, El Paseo Ahumada, con el lugar concreto de la ciudad de Santiago de Chile a la que alude, el Paseo Ahumada. Se hará esta distinción por medio de la cursiva para el título de la obra del poeta y el adaptador, y la minúscula en el artículo para mencionar el espacio físico.
} 
the configuration of the pipeline affects in a crucial way the construction of the receiver's mental image (Ryan, 2011: 17).

La propuesta de Ryan se replantea el rol que juegan las propiedades estructurales y retóricas propias del medio en diversos procesos de remediación (Grusin, 2005: 648), tales como la transposición. En esta misma línea, Karin Kukkonen afirma que el medio determina la forma en que el contenido semántico llegará al receptor y el modo en que lo representará (2013: 75). En el caso de la adaptación es crucial tener esto en cuenta, pues adaptar es transformar, o filtrar. De ahí las palabras de Linda Hutcheon al respecto: "an adaptation is a derivation that is no derivate-a work that is second without being secondary" (Hutcheon, 2006: 9). Precisamente, esta transformación (incremental, a juicio de Sanders, como ya se ha mencionado), implica la puesta en tensión de determinados elementos de la narración y el discurso que influyen en el resultado final del proceso de la adaptación: las cualidades mediales (media affordances) ${ }^{2}$, la lectura del adaptador y los rasgos esenciales del texto lírico, que es el registro del hipotexto.

En su artículo "Narrativity and segmentivity, or poetry in the gutter" (2010), Brian McHale propone un método para hacerse cargo de la dificultad que surge en la transposición de la poesía al cómic. Para el investigador, tanto la traducción como la adaptación son dos formas que favorecen la visibilidad de la interacción entre formatos discursivos tan dispares como el narrativo y el no-narrativo (2010: 27). McHale distingue la segmentividad (segmentivity) como un elemento estructural distintivo en

${ }^{2} \mathrm{El}$ concepto de media affordances proviene de las reflexiones del filósofo James Gibson en su texto (1983). De su aplicación en narratología y teoría de medios, ver Kukkonen (2013) y Kress (2003). Para su aplicación en teoría de la adaptación al cómic, junto al texto de Kukkonen, ver Gutiérrez (2017). Si bien se ha elegido traducir el concepto a "cualidades mediales", debe recalcarse que la traducción no es del todo exacta, por cuanto el concepto affordance no se restringe a las características estructurales de un medio determinado, sino que también de la interacción e influencia recíprocas que se producen entre relato, enunciación y soporte medial. Por ello, se conservará la cursiva. 
la poesía. En su artículo, cita a Rachel Du Preiss quien la define como una práctica en la construcción discursiva en poesía: "the ability to articulate and make meaning by selecting, deploying, and combining segments" (1996: 56). El investigador afirma que la poesía es escritura segmentada, "the kind of writing that is articulated in sequenced, gapped lines and whose meanings are created by occuring in bounded units (...) operating in relation to (...) pause or silence" (McHale, 2010: 51). Es en este rasgo en el que el autor encuentra un vínculo que posibilita la transposición de poesía a cómic.

En la segmentación, pues, está implícita una idea de secuencialidad que se sigue de la creación de significado a partir de los vacíos que se producen entre segmento y segmento. Para McHale, siguiendo las reflexiones de otros autores, esta reconstrucción de la cadena de significados en poesía se origina en la provocación que se hace al lector de llenar ese vacío, que puede estar propiciado por una irrupción en la fluidez gramatical de una frase cortada en dos o más versos que, de algún modo, obligan al lector a repensar su sentido y trazar nuevos puentes entre segmentos (McHale, 2010: 29). De modo análogo, el cómic cimenta su articulación discursiva en la fragmentación y en la complicidad con el lector para poner en movimiento la narración, en un proceso que Sergio Brancato califica de ilusión voluntaria de movimiento (2000: 37). De la misma forma, para McCloud esta ilusión voluntaria constituye el secreto de la mecánica narrativa del cómic, la clausura (closure) (1993: 64-69):

just as the spacing between segments or units of measure provokes meaning-making in poetry, and just as the cut or edit does (more or less conspicuously, more or less subliminally) in movies, so it is the space between the panels that mobilizes meaning-making in comics (McHale, 2010: 31).

Es el lector, en ambos casos, quien reconstruye a través de las 
inferencias la continuidad discursiva en uno y otro lenguaje. La analogía puede llevarse aún más lejos, tomando en consideración el hecho de que en ambos casos — tanto en poesía como en el cómic - la segmentación produce variaciones en el tempo de la enunciación, propone pausas y silencios cargados de significación. En el caso de los poemas contenidos en El Paseo Ahumada, la segmentación no es regular; no hay una métrica definida o estable y ello tiene que ver con el proyecto mismo de Lihn de reproducir las voces de los personajes que habitan ese espacio. De la misma forma, Liván construye las secuencias y compone la página teniendo muy en cuenta la medida de los versos de Lihn.

A este respecto, se pueden apuntar dos reflexiones. En primer lugar, y relativo a la segmentación irregular de El paseo Ahumada, dicho rasgo se vincula con el carácter narrativo que tiende a tener el texto. De hecho, es posible afirmar que los poemas contenidos en El Paseo Ahumada mantienen un sustrato narrativo, manifiesto implícitamente en el "recorrido" que el hablante hace a través de diversas imágenes que retratan los personajes que pueblan dicho espacio urbano. Liván aprovecha este detalle y construye su versión gráfica al modo de un recorrido explícito, en el que desarticula el orden de textos propuesto por Lihn en función de su propia lectura de la obra: el dibujante transparenta su perspectiva, su mirada de la poesía de Lihn a través de su trazo, de la composición de la página y sobre todo por medio de la rearticulación de la obra al modo de un paseo por el Paseo Ahumada. 

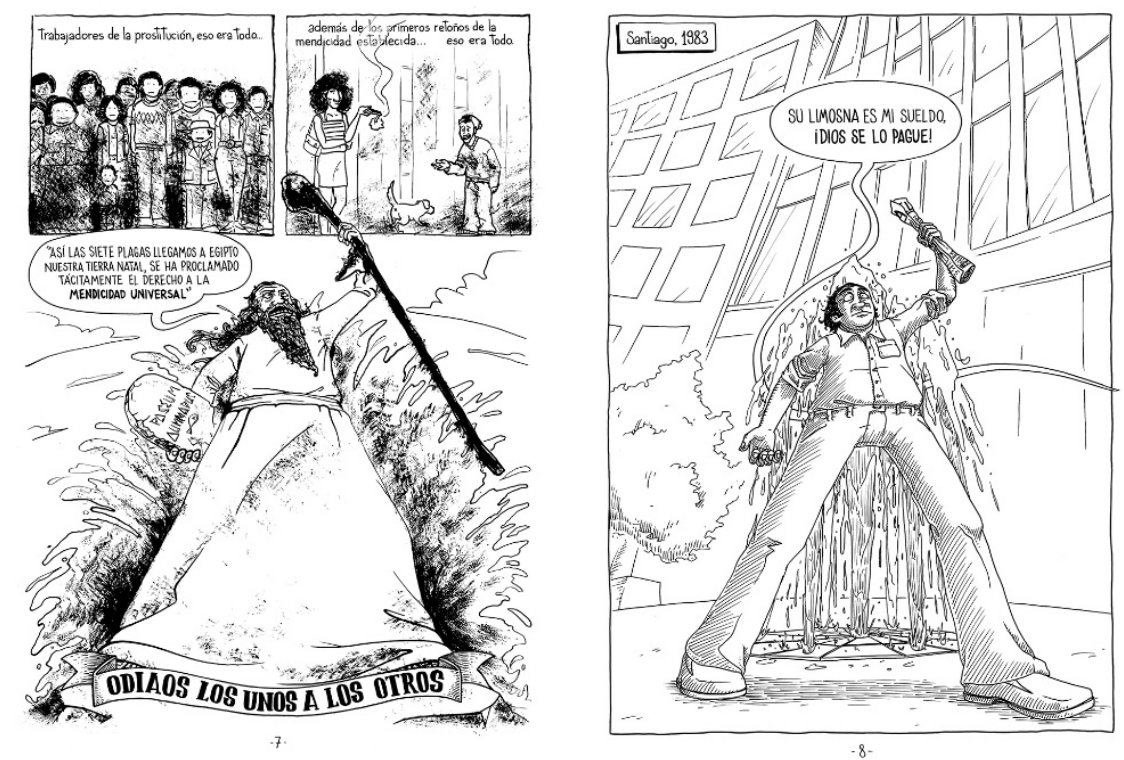

Figura 1. Fragmento de la adaptación de El Paseo Ahumada (Liván, 2013: 7-8)

Si bien hay un reordenamiento de las partes, esta decisión en el proceso de adaptación responde a la necesidad de conservar dicha fluidez narrativa en el discurso secuencial gráfico del cómic. Liván logra esto a través de una de las cualidades mediales fundamentales del medio secuencial: el corte de página (page breakdown). Para mantener el interés del lector, el cómic se sirve de estrategias que producen visualmente una tensión narrativa: a través de la disposición de determinadas imágenes en la última secuencia de la página, se conserva la continuidad con la siguiente por diversos medios. Uno de ellos es estableciendo relaciones de simetría que permiten trasladar la diégesis en espacios y tiempos distintos sin causar disrupciones (VER Fig. 1). En las imágenes citadas, aparece el hablante lírico caracterizado como personaje bíblico replicando los versos del poema "Las 7 plagas del Paraíso Terrenal”: “Así, las siete plagas llegamos a Egipto, nuestra tierra natal” (Lihn, 2010: 37). En la adaptación, el verso con que cierra el poema remata la página, a modo de una consigna que se 
despliega a los pies del personaje que mantiene una postura que remite a Moisés dividiendo las aguas (Liván, 2013: 7). En la página siguiente, aparece el hablante a página completa, delante del chorro del Vivac que se menciona en la obra, sosteniendo la misma posición pero esta vez en una caracterización que lo aproxima más al Enrique Lihn de 1983, año en que se publicó El Paseo Ahumada (Liván, 2013: 8).

Como se ha dicho, la propuesta del adaptador no es antojadiza: responde a la lectura que éste ha hecho de la fuente, que refleja a su vez un juicio acerca de la estructura del hipotexto y que representa a través de las cualidades mediales del cómic a lo largo de toda la adaptación. La fluidez y continuidad en los poemas de Lihn, que a juicio de Liván — por lo que puede verse al leer su versión de El Paseo Ahumada - remiten a la idea de una caminata a lo largo del emblemático paso peatonal, un largo paseo en que el hablante se detiene a escrutar a los personajes que allí conviven:

El Paseo Ahumada opera como el cauce de un río humano, un espacio particular por donde vagan almas estancadas, que creen estar en tránsito, pero que están, en realidad, condenados a esparcirse sin rumbo por este supuesto oasis, espejismo de un pais en "desarrollo", que a poco andar fue invadido por baratijas de plástico, predicadores y los infaltables mendigos y artistas improvisados (Coddou, 2004: 10). 


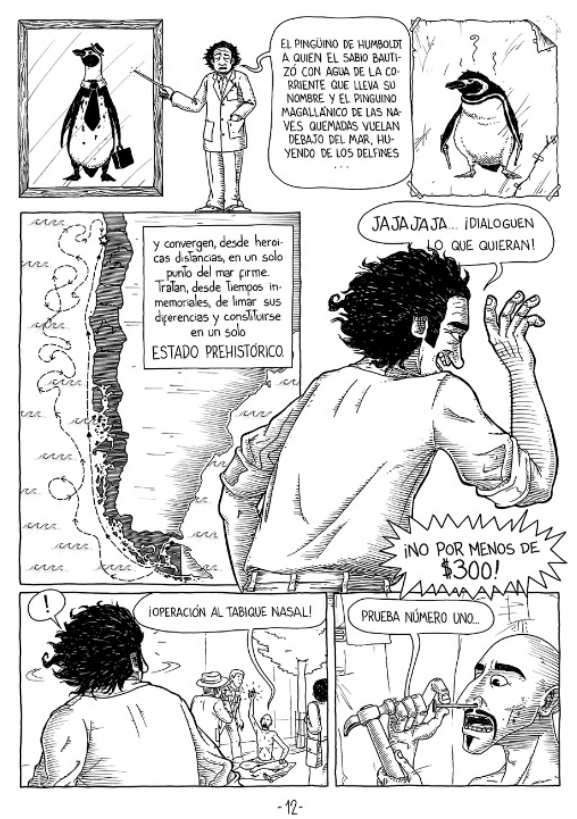

Figura 2. Fragmento de la adaptación de El Paseo Ahumada (Liván, 2013: 12)

En su propia lectura del texto (cuya manifestación es, de hecho la transposición), Liván toma en cuenta estas mismas ideas y, como lector receptivo de la obra, traduce esa fluidez a través de las transiciones de página y de la recursividad, o sea, aprovechando las cualidades mediales del cómic. En este sentido, el caso de la transición desde su adaptación del poema "Nada nuevo en el encuentro de Cachagua entre el de Humboldt y el Magallánico" a "No por menos de 300", que en el hipotexto no son contiguos, ofrece un buen ejemplo de la comprensión del adaptador de la naturaleza "fluvial" del poema: compartiendo la misma plancha, los últimos versos de "Nada nuevo..." y los primeros de "No por menos..." encuentran su continuidad en la voz del hablante lírico, representado en la versión de Liván como una imagen icónica del poeta Enrique Lihn, como ya se ha mencionado. En la mitad de la página se ve al personaje enunciando los últimos versos del poema "Nada nuevo...", en un ademán irónico y burlón y en una actitud corporal que permite interpretar la 
misma actitud del hablante en la fuente: con las palabras "¡dialoguen lo que quieran!", separadas en un verso que parece más una interjección, el hablante ya parece adelantar el resultado estéril de dichas conversaciones con una ironía que se replica visualmente en el hipertexto con la imagen de Lihn dando la espalda a la secuencia que le precede (VER Fig. 2). En ese mismo espacio, sin mediar la división de otra viñeta, irrumpe el texto “¡No por menos de $\$ 300$ !” (idem) encerrado en perigrama dentado y de puntas salientes que representa estridencia y súbita aparición (Gasca \& Gubern, 2011: 279-280); dicho texto es el que da título al poema de la fuente (Lihn, 2003: 25) y abre el poema que se desarrolla brevemente en una secuencia que culmina con el personaje-hablante-Lihn alejándose caminando y, nuevamente, dando la espalda a los textos y acciones. Nuevamente, se produce una transición a la adaptación de un nuevo poema, "Ciegos instrumentales tocan..." (Lihn, 2003: 45) que retrata al personajehablante caminando por el Paseo Ahumada, como un flanêur baudeleriano. Esta es, precisamente, la tónica de la continuidad en la versión de Liván. El dibujante elige representar al hablante en constante movimiento y activamente involucrado en las escenas retratadas/relatadas. Este hecho facilita un desarrollo narrativo propio del cómic, pero que a través de la composición de la página (page layout) y el quiebre de continuidad entre una plancha y otra (page breakdown) permite conservar el vínculo con lo esencial de la fuente. De este modo, y siguiendo las ideas de McFarlane (1982) se separan enunciado y enunciación de modo tal que se produce la particular situación de que un texto narrativo está transponiendo uno de naturaleza lírica.

Precisamente, la segunda reflexión que puede plantearse a la luz de la segmentación y continuidad en la transposición de El Paseo Ahumada se vincula con lo anteriormente mencionado. Liván propone una estrategia interesante al situar al hablante lírico en una figura concreta y encarnada en el discurso mismo del cómic: así, retrata a un Enrique Lihn que se pasea entre los cuchepos y pingüinos con las manos en los bolsillos, observando y oyéndolo todo. Es una suerte de flanêur que es una imagen del hablante 
lírico, con todo lo que este concepto implica: es un reflejo, una repetición con variaciones en palabras de Hutcheon. Es, en fin, una adaptación del hablante mismo que se adecua a las cualidades mediales del cómic.

La propuesta del adaptador de representar al hablante como un cuerpo involucrado en el espacio del Paseo Ahumada, que interactúa con sus personajes y no solamente una voz responde al efecto que genera Lihn en su obra, que Alejandro Zambra comenta al referirse a la persona que encarna el hablante lírico:

no hace otra cosa que callejear, absolutamente inmerso en el mar humano. No busca construir una representación verosímil o universal de la realidad, sino más bien enfrentarla desde su particular y precaria situación; deja entrar, entonces, en sus poemas, esquirlas de un lenguaje que recoge de la calle: coloquialismos, exabruptos, frases de letreros luminosos, recetas para pedir limosna, etc. (Zambra, 2003: 11).

Liván es muy hábil en recabar en las cualidades mediales del cómic para dar cuenta de esas sutilezas en la construcción discursiva, representando un Lihn icónico y simplificado, a ratos caricaturesco (que lo aproxima a la parodia amable y que exacerba el espíritu de adaptación del texto), vestido de forma sencilla y que, por lo mismo, se confunde con los peatones y, de un modo análogo, al Pingüino. Es una similitud en la vestimenta que llama la atención y que sólo al final se interrumpe con una representación distinta de Lihn, en su escritorio trabajando. Aparte de esto, Liván se preocupa de representar al hablante en situaciones dinámicas y activas, y en muchos casos en una actitud interpelativa que compagina que otras lecturas que se han realizado del poema:

E1 Paseo Ahumada, es una reafirmación de la vocación de poe- 
ta-callejero de Lihn, el flanêur que actúa como un testigo-participante, aquel que eleva su voz pidiendo la atención del Pingüino y de sus hermanos subacuáticos, los residuos de la raza, que están atrapados en un paseo que no conduce a ningún lugar, que sólo da la apariencia de tránsito (Coddou, 2004: 10).

Por otro lado, la presencia del personaje-hablante en la versión de Liván tiene otro sentido que acompaña, en cierto modo, esta presencia de testigo-participante de la que habla Coddou: como tal, busca emular la misma función apelativa que cumple en el texto de Lihn hacia la figura del Pingüino, pero con variaciones:

Mi Canto particular (que te interprete, pingüino), producto de la recesión y de otras restricciones

Soy un cantante limitado, un minusválido de la canción

Canto General al Paseo Ahumada

Vuestro monumento viviente (habrá otros, habrá otros: la inmortalidad no es impaciente)... (Lihn, 2003: 32).

En la versión de Liván, se muestra al propio hablante interpelando directamente a los lectores, desde una página organizada con una retícula regular que denota una estabilización del tiempo en que se desarrolla el discurso: en el cómic, el tiempo se mide a través de la composición de viñetas, secuencias y bocadillos (McCloud, 1993; Varillas, 2011), de modo que el espacio de la plancha se transforma en una especie de pauta musical que, de algún modo, guarda cierta similitud con el espacio de la página que ocupa el poema. Al observarla como un todo, vemos la irregularidad de unos versos más largos que otros y de oraciones que se interrumpen para continuar en el verso siguiente que marcan un ritmo de lectura, un patrón de desarrollo discursivo que se construye desde la oralidad de la calle que 
Lihn, tal como lo plantea Zambra, no busca recrear, sino que más bien "se apropia de la jerga callejera para amplificarla a través de versos largos y prosaicos, pero no por ello menos certeros poéticamente" (Zambra, 2003: 10), hecho que apunta a interpelar de modo frontal a los peatones que llenan el Paseo, y en última instancia al lector. Como puede verse, el adaptador se encarga de transponer esa segmentividad de la poesía en los juegos de tempo de las secuencia, alternando retículas regulares con composiciones de página más aproximadas a una función Productiva (Peeters, 2003: 6672).
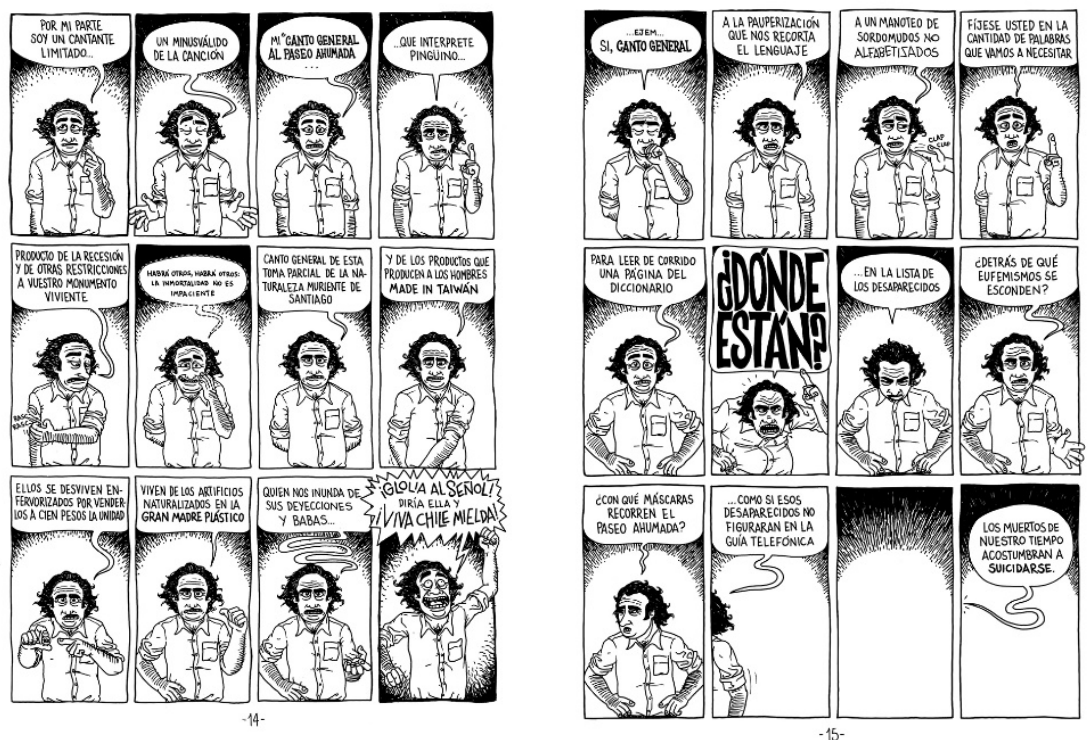

Figura 3. Fragmento de la adaptación de El Paseo Ahumada (Liván 2013: 14-15)

Liván capta el espíritu de esta intención apelativa del poema "Canto general" (Lihn, 2003: 32-34) e instala al hablante mirando al lector a la cara, rompiendo la cuarta pared e involucrándolos directamente con su discurso, que se desarrolla en las secuencias con una gran variedad de gestos y expresiones faciales, en las que evidentemente predomina un cierto hastío, proveniente del peso de la palabra recesión que aparece en varios de los poemas, y también el fantasma de la Dictadura, instalado 
entrelíneas y acechando su creciente ira (VER Fig. 3). En este sentido, el cierre de la secuencia resulta interesante: tras hablar de los desaparecidos, el propio hablante sale de la escena, dejándonos el espacio vacío de la viñeta y luego un globo con un verso llenando esa ausencia del "fuera de campo" (hors-champ). En la fuente, el verso reproducido en esa última viñeta marca un cambio de ritmo en el poema: precede a otro mucho más largo, a otra configuración de ritmo que Liván recrea a través de la propuesta de una composición de página totalmente distinta en la plancha siguiente (VER Fig. 4).

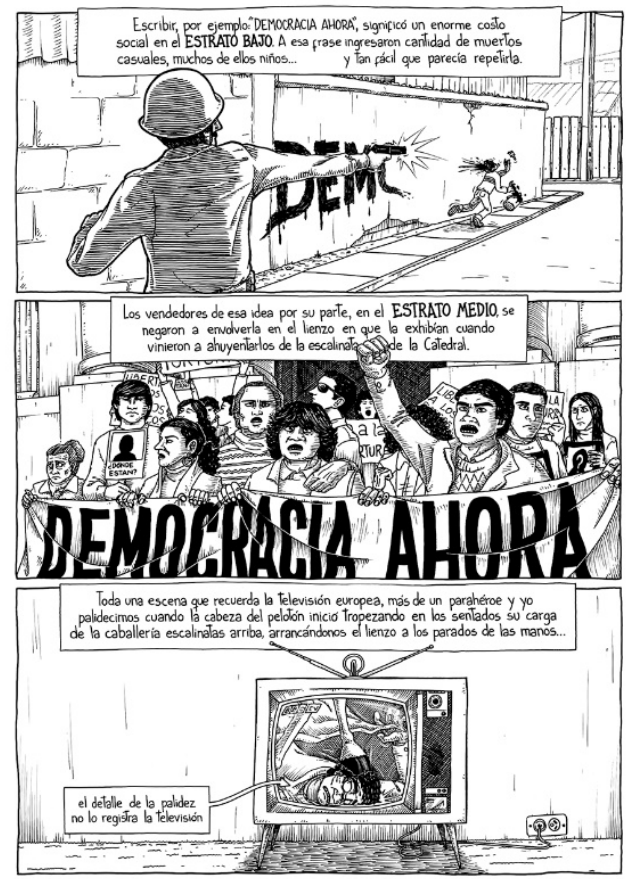

Figura 4. Fragmento de la adaptación de El Paseo Ahumada (Liván, 2013: 16)

Como se ha podido constatar, las cualidades mediales del cómic se ponen al servicio de la transposición para producir una reescritura lo más diáfana posible que, si bien transgrede ciertas reglas de la fuente, no la vuelve distante o irreconocible. A este respecto, es pertinente considerar las 
palabras de Kukkonen acerca de la necesidad de las cualidades mediales en el proceso de adaptación, y también como modo de asimilar estrategias de adaptación al momento de analizar una transposición: de acuerdo con la investigadora, "comics have to translate narrative strategies from the written word into images, words and sequence" (2013: 75). Son las cualidades que distinguen la construcción discursiva del medio secuencial las que se ponen al servicio del relato para generar un producto autónomo que, no obstante, se vincule con su fuente.

Ahora bien, como ya se ha acotado, la literatura sobre cualidades mediales del cómic se ha centrado en las adaptaciones de un medio narrativo a otro. El caso de la poesía es distinto, y los planteamientos de McHale han abierto una posibilidad y aportado luces al respecto, como ya se ha constatado en lo comentado hasta el momento. La segmentividad de la poesía (acaso uno de sus affordances) encuentra su homólogo en algunos de las cualidades mediales del cómic, como lo son el tempo de la secuencia o la composición de página. La articulación del discurso narrativo en el cómic, de acuerdo con Groensteen, se desenvuelve en el espacio de la página a través del arreglo o composición de los elementos fundamentales retóricos de la narrativa secuencial, como la secuencia y el corte de página y la composición, junto con otros factores en los que se involucran las tensiones entre texto e imagen, considerando la taxonomía de uso de página propuesta por Peeters. Todos estos elementos — cualidades mediales del cómic - sirven a Liván para reconstruir la naturaleza enunciativa de la fuente sin transgredir las reglas de uno u otro medio.

Ya se ha mencionado que la obra de Lihn permite su adaptación al cómic, entre otras razones, por la naturaleza de su discurso que se aproxima a lo narrativo. Para McHale, dicho requisito es esencial, pues permite la transposición considerando la segmentación como base del proceso:

in poetic narratives, narrative's own segmentation interacts with the segmentation "indigenous" to poetry to produce a complex counterpoint among segments of different scales and kinds (2010: 30). 
Esos contrapuntos son los que le dan rasgos distintivos inéditos a la transposición y le permiten distanciarse de su fuente, pero sin hacer del todo irreconocibles las trazas de la fuente. Ahora bien, como se ha referido anteriormente, para el caso de El Paseo Ahumada no es suficiente establecer el contrapunto entre dos modos de segmentación como lo hace McHale. Más bien, hay que tomar en consideración otros factores: del "contrapunto" o "acorde" del que habla el investigador se produce una tensión entre fuente, cualidades mediales y poética visual (ontología visual) de Liván. Y esa ontología visual tiene anclaje en la parodia positiva que, a su vez, busca jugar al final con el contrapunto metatextual del cierre de su versión de El Paseo Ahumada. En el apartado siguiente se precisarán estos puntos.

En definitiva, las cualidades mediales del cómic, un medio esencialmente narrativo, se adaptan a las necesidades o requerimientos del poema en lo que respecta a la fluidez e interconexión para obtener el mismo resultado de unidad y coherencia que emerge desde la construcción de hablante-paseante ya comentada. En ese sentido, deja de ser una traducción literal pues el adaptador elige alterar el orden temático con miras a enfatizar el paseo, el flanêur del hablante.

\section{EL PROCESO DE ADAPTACIÓN: PUNTOS DE TENSIÓN}

Tras revisar algunas reflexiones en torno a la segmentividad de la poesía y los pormenores de su transposición al medio secuencial, es pertinente adentrarse en el modo en que la adaptación tensiona con las cualidades mediales del cómic y la segmentación del discurso "narrativo" que se traza tanto en la estructura como el contenido del discurso de la fuente (principalmente a través de la idea de "paseo" del hablante lírico a lo largo del espacio del Paseo Ahumada) y que se resuelve en la lectura personal del adaptador que se manifiesta a través de la enunciación, es decir, su ontología visual. 
Previamente, se ha dicho que en la adaptación de El Paseo Ahumada hay una re-segmentación a raíz de las tensiones producidas por el contrapunto o acorde del que habla McHale cuando se refiere al ejemplo de la versión gráfica de The waste Land de Rowson (McHale, 2010: 46); no obstante, la segmentación en el caso de la versión de Liván es la base de la tensión de otros factores propios de la adaptación como proceso. Ciertamente, hay en la transposición mucho más que una reversión de los modos de enunciación; en el proceso de adaptación entran en juego las cualidades mediales que lleva a la relación entre fuente y versión a una tensión que trasciende la mera analogía, como plantea McHale: "we cannot map the gaps of Elliot's The wasteland one for one directly onto the gutters of Rowson's version; one version is not homologous with the other. But the two versions are analogous" (2010: 46). En efecto, tomando en consideración lo ya discutido acerca de las cualidades que definen un medio determinado, la mirada particular del adaptador (su ontología visual, como ya se precisará) y otros aspectos, la reescritura de Liván implica una lectura $\mathrm{y}$, como se verá, es una revisión paródica pero en su sentido "serio"3: la adaptación de El Paseo Ahumada, con su representación caricaturesca del hablante, es un respetuoso saludo a la fuente, un homenaje que deviene reconstrucción, reescritura tensionando por un lado las cualidades mediales y la mirada del autor, todo ello sobre la base de los desafíos de la segmentación en el proceso de transposición.

Como puede verse, la propuesta del adaptador responde principalmente a dos cuestiones: por un lado, a su interpretación personal del texto, a su lectura del poema de Lihn plasmada en la aplicación de la técnica del dibujo y las decisiones relativas a la composición de la página (page layout), a su visión de la obra manifestada a través de la técnica: en palabras de Pascal Lefevre, de la ontología visual del adaptador (Lefevre,

\footnotetext{
${ }^{3}$ En efecto, Linda Hutcheon (1978: 179-181) hace una clara distinción al respecto, al abordar la parodia como concepto desde su etimología: de este modo, separa la parodia burlesca, el "contra-canto" que busca cuestionar la obra que referencia, y la parodia "seria", el "canto paralelo" en que el autor hace un guiño, un saludo, un gesto de homenaje a la fuente que está referenciando.
} 
2007: 8), es decir, la visión del autor que rezuma de la articulación discursiva de la adaptación.

Por otra parte, la propuesta de Liván se construye enmarcada en los límites expresivos del medio en que se ha llevado a cabo la versión. Como ya se ha planteado, los medios aportan información desde su materialidad y estructura, de modo que redefinen el contenido de lo adaptado y, sobre todo, el modo en que se expone discursivamente (Ryan, 2004: 1). En dos modos de expresión tan divergentes como el cómic y el poema, la tensión entre la fuente, la ontología visual del adaptador y los límites del medio tiene alcances críticos, más aún cuando el adaptador enfrenta el desafío de trasladar a un dispositivo narrativo como lo es el cómic un texto lírico.

Una de las soluciones más elegantes propuestas por el adaptador emerge desde la estructura total de su texto: como ya se mencionó, Liván articuló su trabajo a modo de un continuo en el que el hablante lírico, encarnado en un personaje que es una representación de Enrique Lihn, recorre el Paseo Ahumada callejeando inmerso en la multitud, muy al modo del flanêur baudelaireano. A juicio de Zambra, el paralelo es evidente, y el adaptador gráfico lo toma en cuenta. Asimismo, aprovecha que los poemas contenidos en El Paseo Ahumada son unidades discretas, y altera el orden propuesto en la fuente para acomodarlo a las necesidades del medio secuencial: de este modo, es capaz de resituar los poemas a modo de piezas gráficas que se yuxtaponen en un flujo continuo, que emula la versificación de Lihn de escasa puntuación y extensas frases.

Como puede verse, el adaptador saca provecho de la naturaleza narrativa del cómic, pero sin desconocer las funciones que rigen el texto lírico que da origen a la transposición. Como hablamos de adaptación desde el poema al cómic, hay que dejar de lado lo narrativo, y más bien centrar la mirada en el modo en que se desarrolla el discurso lírico, que aprovecha la plasticidad de la gramática y la versatilidad de la sonoridad de la lengua, estableciendo contrapuntos y simetrías tanto semánticas como fonéticas, en versos como "Huríes, diría yo/las heroínas de ese trabajo que vienen y van" (Lihn 2003: 56). En un medio evidentemente visual como lo es el 
cómic, emular este tipo de juegos debe hacerse desde la composición de la página, de la desarticulación de las secuencias, de la disposición de los textos y las imágenes en equilibrio o desequilibrio.

Precisamente, una de las grandes ventajas formales del medio secuencial es su plasticidad espacial en lo discursivo. De acuerdo con lo que plantea Groensteen (2007: 21), la construcción del discurso del cómic tiene sus cimientos en el espacio artrológico de la página, es decir, en la articulación del espacio del ámbito de la plancha con el desarrollo del tiempo narrativo en el caso de un relato. Para el caso del poema, la propia secuencialidad del lenguaje y su gramática ordenan la fluidez del discurso, pero también le da plena libertad al adaptador para modular el texto no ya en función del tiempo que ocupa en desarrollarse el discurso o la recitación, sino que el espacio en el cual ésta se puede desenvolver visualmente.

Un ejemplo ilustrativo de lo aquí expuesto es la adaptación que Liván hace del poema "Noticias de un astronauta del futuro candidato a la presidencia del mundo". En ella, el adaptador recoge la imagen mística del astronauta que se pasea por los medios masivos y el Paseo en el poema de Lihn: "Helo aquí ni Satanás ni Belial ni Luzbel, un simple tecnócrata divinamente preparado/para todas las emergencias del ascenso y el descenso" (Lihn, 2003: 22). En la versión gráfica, aparece representado a modo de estatuilla en una especie de gruta, rodeado de plaquitas como las que acompañan a los santos en capillas e iglesias del centro, sólo que en ellas aparecen los versos que cierran el poema: "Basta de todas esas farsas opulentas Al hoyo negro con todos los emblemas, información y no profecías/ queremos, y que aterrice, por fin ese zote" (Lihn, 2003: 24). El adaptador dispone los versos dispersos en la pared, pero su composición sugiere un orden de lectura convencional de izquierda a derecha y de arriba hacia abajo. La parte inferior de la página ostenta una viñeta con la forma de una pantalla de televisión que acaba de ser apagada mientras que, fuera de campo, una voz (la del hablante ya ausente nuevamente de la escena) replica uno de los últimos versos del poema. 


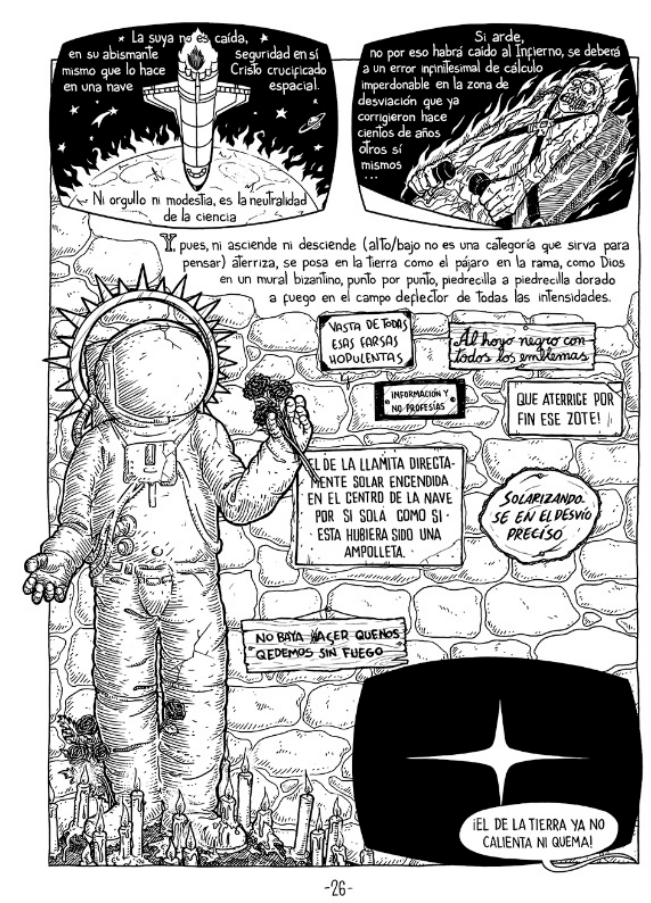

Figura 5. Fragmento de la adaptación de El Paseo Ahumada (Liván, 2013: 26)

El discurso no pierde su fluidez y ritmo, sólo se transmuta a la espacialidad de la página, abriendo al lector un nuevo horizonte de interpretaciones de las imágenes sugeridas por el poema. La secuencialidad y narratividad queda suspendida en este fragmento, favoreciendo la emergencia de una especie de "lírica visual" que se articula en torno a la artrología de la página y su composición, pero sin perder el dinamismo del cómic que, a pesar del arreglo de la plancha, sugiere un "recorrido" al ojo del lector que sostiene la ilación discursiva particular de estos poemas de Lihn (VER Fig. 5).

Estrechamente relacionado con esto está la composición de la página y las tipologías que Benoit Peeters distingue en su trabajo Lire la bande desinée. Allí, Peeters propone cuatro tipologías de plancha, basadas en las relaciones entre la mayor o menor dependencia entre la narración y 
la composición de la página por un lado, y el dominio de una u otra, por otro lado. De este modo, se desglosan cuatro tipologías: la convencional, la decorativa, la retórica y la productiva4 (Peeters, 2003: 49-75).

Este último uso, precisamente, es al que recurre Liván para resolver las incompatibilidades retóricas y formales entre cómic y poesía: por medio de un arreglo de la página que superpone la composición por sobre el desarrollo discursivo, de modo tal que se tiende a disminuir el peso narrativo de éste en desmedro de su desarrollo estético. Este efecto, visualmente, emula el que lingüísticamente ostenta el trabajo de Lihn.

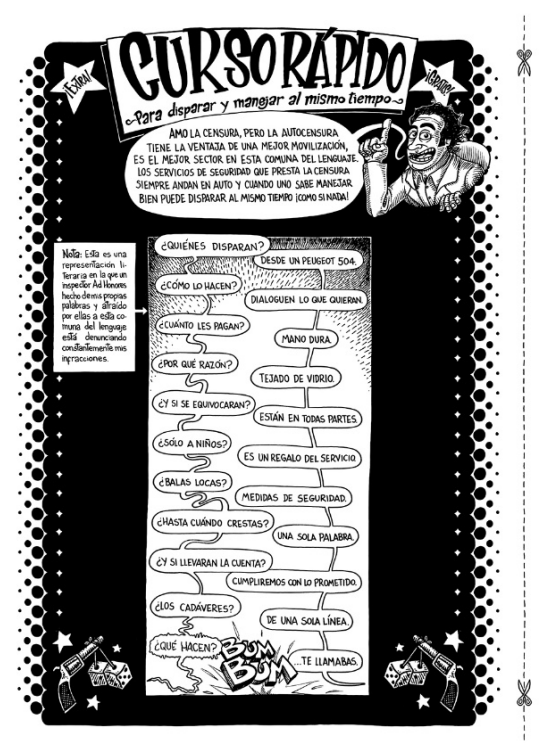

Figura 6. Fragmento de la adaptación de El Paseo Ahumada (Liván, 2013: 30)

${ }^{4}$ La concepción convencional de la página, como su nombre indica, plantea una indepen-
dencia de la narrativa y la composición de la plancha y un evidente dominio de la primera.
La concepción decorativa favorece la composición sobre la narrativa e implica también
una independencia entre las partes. El uso retórico de la página, por otra parte, exige
la interdependencia de composición y narrativa, de modo que ambas se complementan,
siempre en función de la narrativa que predomina sobre la composición. Por último, el
uso productivo considera la misma interdependencia que el anterior pero con un dominio
de la composición. El ejemplo clásico de esta última tipología son los cómics de Winsor
McCay. 
Un ejemplo concreto de ello es la adaptación del poema previamente comentado, pero se pueden hallar otros casos concretos que ofrecen la posibilidad de un análisis interesante de la lectura que Liván propone de la fuente. En primer lugar, la versión del poema “Curso rápido para aprender a disparar y manejar al mismo tiempo" está reconstruido en una sola plancha al modo de un inserto publicitario: el adaptador favorece la composición de la página para articular la sucesión de versos que aparentemente no guardan ninguna coherencia, pero que a la vez evoca un interrogatorio: “¿Quiénes disparan? Desde un Peugeot 504/¿Cómo lo hacen? Dialoguen lo que quieran/ ¿Cuánto les pagan? Mano dura...” (Lihn, 2003: 60). Liván contrapone las dos partes de cada verso en una especie de diálogo en que los globos están unidos entre sí, al modo de dos cadenas que corren paralelas y desembocan, tras una temblorosa pregunta final y una inquietante respuesta, en dos disparos sugeridos por una onomatopeya (VER Fig. 6).

Por último, la versión gráfica de "Tocan el tambor a cuatro manos" ofrece un uso productivo de la página aplicado con mucha fineza: en primer lugar, la secuencia del encabezado de página sigue un raccord hilado por la onomatopeya de la sirena de una patrulla que atraviesa de un cuadro a otro. Luego, en la zona media e inferior de la página, el dibujante representa visualmente la metadiscursividad del poema sacando provecho del formato mismo del medio secuencial al simular en el confín de la viñeta el borde de papel arrugado de una página arrancada y, debajo de ella, la voz del hablante encarnada en otra imagen de Lihn que quiere referir no ya a dicha máscara textual, sino que al autor mismo (entendiendo que, inescapablemente, no es más que una representación icónica de la voz que sugiere la presencia fantasmal del autor reflejándose en su propio lenguaje). Por medio de un globo que se distribuye entre ambos cuadros con la frase "Y yo... ¿para qué escribo?", enlaza estos dos planos discursivos, que revela a un Lihn girándose en un gesto metareflexivo, pues parece mirar por sobre su hombro algo que hay más allá de lo que está explícitamente representado en la página (VER Fig. 7). Esta reescritura de los versos del 
poeta opera como juego de espejos del propio poema de Lihn, que refiere a su trabajo anterior "Porque escribí", de La musiquilla de las pobres esferas (1969).

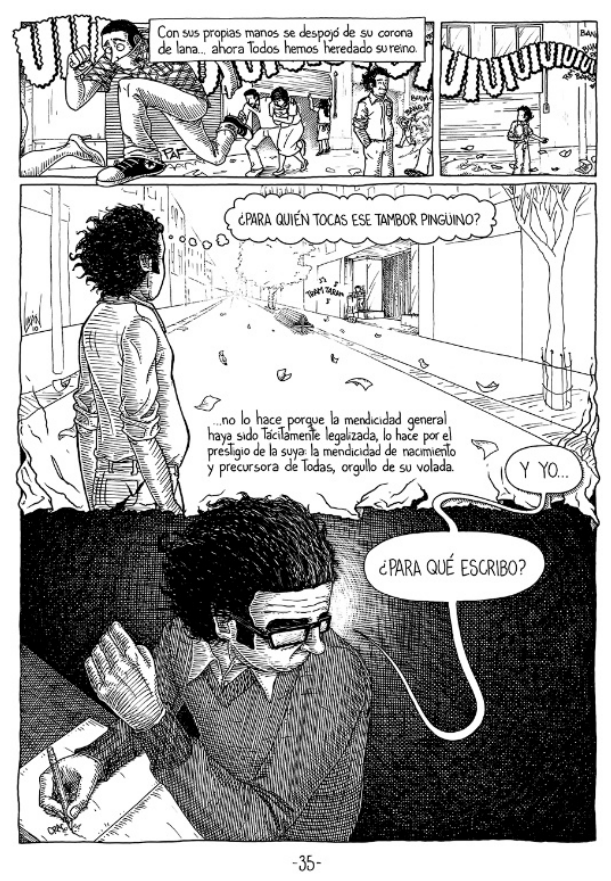

Figura 7. Fragmento de la adaptación de El Paseo Ahumada (Liván, 2013: 35)

Como ha podido verse, la adaptación del poema al cómic reviste una serie de problemáticas discursivas, pero también representa para el autor el desafío — y la oportunidad — de adoptar una postura frente al texto versionado, transformándolo, adaptándolo, en el sentido más biológico del término: adecuando un texto a otra forma discursiva, haciéndolo prosperar semántica y semióticamente proponiendo una audaz simbiosis entre dos formas aparentemente irreconciliables, tal como parece representar Liván, metafóricamente, con la ilustración que abre su personalísima adaptación de El Paseo Ahumada (VER Fig. 8). La catedral de Santiago junto al moderno edificio hablan mucho de la adaptación y sus procesos: el escenario de la fuente, el poema de Lihn, no consideraba esa colosal construcción de 
espejos que refleja la antigua edificación, haciéndole eco, reproduciéndola como Liván reprodujo, con variaciones, El Paseo Ahumada. La elección de dicha imagen para iniciar su obra no es casualidad: da cuenta del paso del tiempo, habla de una lectura y una reescritura del texto de 1983. Habla de nuevos lectores para las mismas ideas, pero transmutadas por las cualidades mediales del cómic.

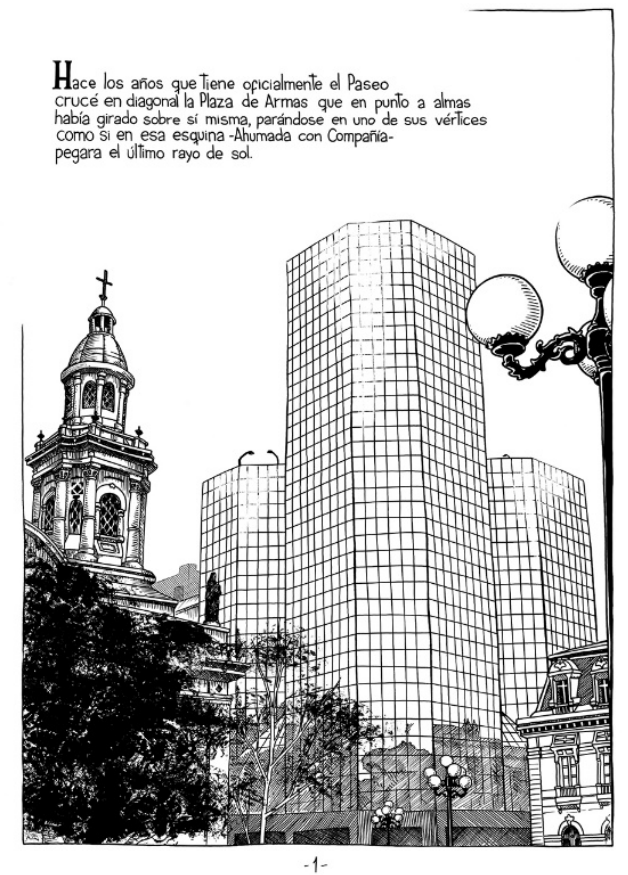

Figura 8. Fragmento de la adaptación de El Paseo Ahumada (Liván, 2013: 1)

Precisamente, tomando en cuenta la ilustración citada, es posible concebir el proceso de adaptación como una forma de posproducción del modo en que la entiende Bourriaud:

las operaciones de las que se trata no consisten en producir imágenes de imágenes, lo cual sería una postura manierista, ni en lamentarse por el hecho de que todo "ya se habría hecho", sino 
en inventar protocolos de uso para los modos de representación y las estructuras formales existentes (2004: 14).

La adaptación es una forma de posproducción, por cuanto la transposición, a través de las cualidades mediales, reescribe el relato en virtud del formato en el que se desarrolla el hipertexto. En el caso de Liván esto cobra mayor relevancia. La postproducción desafía a la forma, y la llama a readecuarse, adaptarse en el sentido biológico para satisfacer al mensaje y reconducir y recablear una lectura del adaptador para otro receptor en quien resuena el eco de la fuente, un eco que, después de todo, no es tan disonante o extraño como podría creerse en un principio:

one surprising finding of this analysis is that comics appear to be more akin to poetry, even to prestigious avant-garde poetry, than we might have supposed. Comics, too, like poetry, are measured and countermeasured; they sound chords of segments. And comics, also like poetry, elicit meaning in the place where meaning stalls out -in between, in the gutter (Mc Hale, 2010: 46).

Ciertamente, las cualidades mediales del cómic no están a merced de la secuencialidad narrativa; más bien, ofrecen incalculables posibilidades que abarcan desde la más férrea causalidad hacia la más pura abstracción. El acotado espacio de la plancha es más bien la ventana a un amplísimo universo de enunciación en que lo visual entra en conflicto con lo textual generando resoluciones inéditas como ha podido verse en el caso de El Paseo Ahumada, y que puede constatarse, asimismo, en otras transposiciones gráficas de poesía de Enrique Lihn como la de Jorge Quién Nada se pierde con vivir (2013), que extrema las cualidades mediales del cómic en una tentativa de apropiación de la fuente tensionando referencias a la Dictadura en Chile con las marchas estudiantiles de 2006. El campo de 
la adaptación al cómic es, pues, muy fértil y puede abrir a más profundas reflexiones en torno a las fronteras de adaptación y apropiación tanto en los recursos retóricos y estructurales mediales como su contenido y enunciación.

\section{REFERENCIAS BIBLIOGRÁFICAS}

BARBIERI, D. (1998). Los lenguajes del cómic. Barcelona: Paidós.

BAETENS, J. (2011). “Abstraction in comics". Substance 40(124), 94113.

BENNETT, T. (2014). "Beyond 'Sequential Art'”. Image\&Narrative 15 (2), 106-123.

BOURRIAUD, N. (2004). Postproducción. Buenos Aires: Adriana Hidalgo.

BRANCATO, S. (2000). Fumetti: guida ai comics nel sistema dei media. Roma: Datanews.

CHATMAN, S. (1978) Story and Discourse: Narrative structure in fiction and film. Ithaca: Cornell University Press.

CODDOU, S. (2004). "Enrique Lihn: 'El Paseo Ahumada': Spleen de Santiago". El Mercurio, 1 de febrero, 10E.

DU PREISS, R. (1996) “Codicil on the definition of poetry". Diacritics 26 $(3 / 4), 31-56$.

FREZZA, G. (1999). Fumetti, anime del visibile. Roma: Meltemi.

GASCA, L. y GUBERN, R. (2011). El discurso del cómic. Madrid: Cátedra.

GIBSON, J. (1971) “The information available in pictures". Leonardo 4.1, 27-35.

(1986). The ecological approach to visual perception. Hillsdale: Laurence Erlbaum.

GROENSTEEN, T. (2007) The system of comics. Trads. Bart Beaty y Nick 
Nguyen. Jackson: University Press of Mississippi.

GRUSIN, R. (2005). "Remediation". En Routledge encyclopedia of Narrative Theory, 648-649. Londres: Routledge.

GUTIÉRREZ G-H, J. (2017). “Tres sutilezas en la adaptación gráfica de Peter Kuper de La Metamorfosis de F. Kafka”. En Refracciones: nueve miradas sobre discurso y medios, en J. G-H. Gutiérrez (ed.), 93-107. Santiago: Cuarto Propio.

HUTCHEON, L. (1978). “Ironía, parodia, sátira”. Poetique 36, 173-193. (2006). A theory of adaptation. New York: Routledge.

JORGE QUIÉN (2013). Nada se pierde con vivir. Santiago: Das Kapital.

KUKKONEN, K. (2013). Studying Comics and Graphic Novels. Oxford: Wiley-Blackwell.

KRESS, G. (2003). Literacy in the new media age. Londres: Routledge.

LEFEVRE, P. (2007). "Incompatible visual ontologies? The problematic adaptation of visual images". En Film and Comic Books, I. Gordon, M. Jancovich y M. McAllister (eds.), 1-12. Jackson: University Press of Misssissippi.

LEITCH, T. (2003) "Twelve Fallacies in Contemporary Adaptation Theory”. Criticism 45(2), 149-171.

LIHN, E. (2003). El Paseo Ahumada. Santiago: UDP Ediciones.

LIVÁN. (2013). El Paseo Ahumada de cuchepos y pingüinos. Santiago: Das Kapital.

MCCLOUD, S. (1993). Cómo se hace un cómic: el arte invisible. Barcelona: Ediciones B.

MCFARLANE, B. (1996). Novel to film: an introduction to the Theory of Adaptation. New York: Oxford University Press.

MCHALE, B. (2008). "Beginning to Think about Narrative in Poetry". Narrative 17(1), 11-27.

(2010). "Narrativity and Segmentivity, or, Poetry in the Gutter". En Intermediality and storytelling, Marie-laure Ryan et al. (eds.), $27-$ 
48. Berlin: De Gruyter.

ONG, W. (2006). Oralidad y escritura: tecnologías de la palabra. FCE: Buenos Aires.

PEETERS, B. (2003). Lire la bande desinée. Barcelona: Flammarion.

RYAN, M-L. (2004). "Introduction”. En Narrative across Media, M-L. Ryan (ed.), 1-40. Nebraska: University of Nebraska Press.

SANDERS, J. (2006). Adaptation and appropriation. New York: Routledge.

VARILLAS, R. (2009). La arquitectura de las viñetas: texto y discurso en el cómic. Sevilla: Viaje a Bizancio.

ZAMBRA, A. (2003). "Prólogo". En El Paseo Ahumada, Lihn, E., 7-13. Santiago: Ediciones UDP.

Recibido el 9 de marzo de 2018.

Aceptado el 19 de julio de 2018. 
